\title{
Comparison of IEEE 112 and New IEC Standard 60034-2-1
}

\author{
Wenping Cao, Member, IEEE
}

\begin{abstract}
This paper describes a comparative study of induction motor testing standards IEEE 112 and newly published IEC 60034-2-1, primarily used in the United States and Europe, respectively. IEC 60034-2-1 has been refined from its earlier version IEC 60034-2 with reference to the IEEE 112. Six induction motors are tested following the two standards and the results are compared with regard to their instrumental accuracy and testing procedures. Power loss results are validated by the calorimetric method. A quantitative method is devised to evaluate the measurement uncertainty that can be interpreted into an efficiency deviation by quadrature addition. This paper is aimed to provide a guideline on interpreting the measured machine efficiency values using these standards and to validate the new IEC standard.
\end{abstract}

Index Terms-Calorimetry, IEC, IEEE standards, induction motors, loss measurement.

\section{INTRODUCTION}

$\mathbf{I}$ $\mathrm{T}$ is well known that induction motor testing standards vary significantly in their defined methodologies, instrumentation accuracy, and testing procedures. Sometimes, the efficiency value for the same motor can differ by $5 \%$ with different standards [1]. Even though the same standard is used in experimental tests, the machine efficiency can still vary by more than $2 \%$ when performed in different testing sites or by different testers [2]. Although some authors have suggested working toward a worldwide uniform standard for the testing of induction motors [3]-[5], this is far cry from an easy task. The difficulties are partially due to diverse sources of measurement uncertainty and lack of accurate uncertainty estimation techniques.

IEEE 112 [6] is perhaps the most widely adopted standard in industry. Although it is primarily used in the United States, some international standards are in line with it such as the Canadian standard C390-93 [7]. In Europe, the International Electrotechnical Commission (IEC) standard 60034-2 [8] was in use until recently. This was a relatively easy standard to apply in practice and required little information in determining the winding temperature and stray-load loss. As a result, it suffered from high measurement uncertainties and had been criticized for many years [4], [9]-[12]. The new standard IEC 60034-2-1 [13] was published in November 2007 and refined from its previous version with significant reference made to IEEE 112. In this paper, IEEE 112 serves as a yardstick for comparison purpose.

Manuscript received December 10, 2008; revised January 5, 2009. First published August 7, 2009; current version published August 21, 2009. Paper no. TEC-00477-2008.

The author is with the School of Science and Technology, University of Teesside, Tees Valley TS1 3BA, U.K. (e-mail: w.cao@tees.ac.uk).

Color versions of one or more of the figures in this paper are available online at http://ieeexplore.iee.org.

Digital Object Identifier 10.1109/TEC.2009.2025321
TABLE I

InSTRUMENTATION ACCURACY AND EFFICIENCY ESTIMATION (IN PERCENT)

\begin{tabular}{|l|c|c|}
\hline \multicolumn{1}{|c|}{ Variable } & IEEE 112 & IEC 34-2-1 \\
\hline Instrument transformer & 0.5 & 0.3 \\
\hline Voltage & 0.2 & 0.2 \\
\hline Current & 0.2 & 0.2 \\
\hline Power & 0.2 & 0.2 \\
\hline Torque & 0.2 & 0.2 \\
\hline Speed & $1 \mathrm{rpm}$ & $1 \mathrm{rpm}$ \\
\hline Frequency & 0.1 & 0.1 \\
\hline Resistance & 0.2 & 0.2 \\
\hline Temperature & $1^{\circ} \mathrm{C}$ & $1{ }^{\circ} \mathrm{C}$ \\
\hline Efficiency by $W C E$ & 0.31 & 0.33 \\
\hline Efficiency by $R P B E$ & 0.17 & 0.18 \\
\hline
\end{tabular}

By investigating the measurement uncertainties in experimentally determined induction motor efficiency, each error source's relative influence on the losses and efficiency can be estimated. As a consequence, a realistic perturbation-based estimation (RPBE) method is proposed that incorporates all the significant error sources and that can be used to evaluate the overall accuracy of loss and efficiency calculations.

A test rig is set up to directly measure the machine power loss by the standard methods and a high-precision $30 \mathrm{~kW}$ calorimeter is also employed to justify these power loss measurements. Six general purpose three-phase induction motors rated between 5.5 and $150 \mathrm{~kW}$ are carefully tested using IEC 60034-2-1 and IEEE 112-B methods.

The aims of this paper are to assist in interpretations of measured efficiency data and also to check the effectiveness of IEC 60034-2-1.

\section{IEEE 112 AND IEC 60034-2-1}

IEEE 112 has been widely accepted as being a milestone in induction motor testing standards and proven to be reliable and consistent while the newly published standard IEC 60034-2-1 has not yet been validated in the literature.

In order to compare the two standards, three error sources are considered here: instrumental, methodological, and human factors. These in combination determine the overall accuracy of power losses and efficiency of the induction motor under test.

\section{A. Instrumentation Accuracy}

Without a doubt, instrumentation accuracy plays a key role in an experimental measurement. Shown in Table I are the instrumentation accuracies specified in the two standards. It can be seen that the new IEC standard defines nearly the same instrumental accuracy as the IEEE counterpart, and thus, represents 
a significant improvement on its previous version of the IEC standard.

However, using an instrument having similar accuracy does not necessarily yield similar results. The differences arise from diverse methodologies and testing procedures defined in the standards, and human involvement in the measurement.

\section{B. Methodology}

The two standards define several methods to determine the losses and efficiency. This paper focuses particularly on the input-output methods with loss segregation, which are extensively used in industry.

First, to determine the stator conductor loss, it is necessary to acquire either stator winding resistances or temperatures under any testing conditions. IEEE 112 requires a stator winding resistance to be measured when the motor is cold prior to any heat run test. This serves as a reference resistance and is later used to calculate winding resistances for all load conditions, with measured winding temperatures. Clearly, some temperature sensors are needed to obtain the winding temperature, and thus, this approach is intrusive to those induction motors in service. On the contrary, in IEC 60034-2-1, the winding resistance is directly measured before the highest load and after the lowest load points by shutting down the motor, measuring the terminal resistance, and extrapolating back to zero time. The actual winding temperature is not required. This method provides two readings of the winding resistance, corresponding to the rated and lowest load points. Winding resistances for higher loads than $100 \%$ are assumed to be that for the rated load while winding resistances for lower loads are assumed to be the arithmetic mean of the two readings using a straight line interpolation. An obvious advantage is the elimination of the need for internal temperature sensors, and therefore, the test can be applied to a wide range of induction motors without having to take them apart. However, accurate winding temperature is not guaranteed.

In terms of core loss determination, the two standards define similar no-load tests to segregate the friction and windage losses from the core loss. In IEEE 112, core loss should be the same for all load points, but in the IEC standard, the core loss varies with load, depending on the resistive voltage drop in the stator winding, according to the equation

$U_{r}=\sqrt{\left(U-\frac{\sqrt{3}}{2} \times I \times R \cos \theta\right)^{2}+\left(\frac{\sqrt{3}}{2} \times I \times R \sin \theta\right)^{2}}$

where $U, I$, and $R$ are the line voltage, current, and resistance, respectively, and $\theta$ is the power factor angle.

It is obvious that the IEC method is more precise than the IEEE method in this respect since the actual magnetization voltage (and thus, core loss) is determined by deducting the stator winding resistive voltage drop from the phase voltage.

For stray-load loss determination, the two standards use similar techniques. Namely, the residual loss is first derived by removing determinable traditional losses from the total loss, and then, the curve is smoothed to find the stray-load loss using a linear regression analysis. A minor difference is the correlation

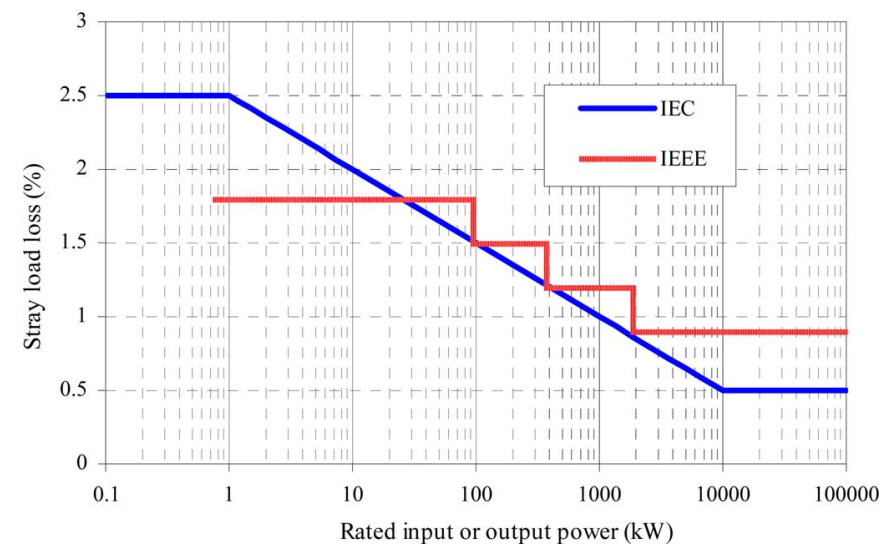

Fig. 1. Assigned allowances for stray-load loss.

coefficient in the curve fitting of stray-load loss, where IEEE 112 specifies a minimal of 0.9 and the IEC standard, 0.95 .

In case a direct determination of stray-load loss is not feasible, this loss component can be estimated by both standards using given allowances that are a function of either input power (IEC 60034-2-1) or output power (IEEE 112). These ratios are plotted in Fig. 1 for comparison. Although these allowances have statistical implications of stray-load loss and are already better than a fixed allowance, as defined in IEC 34-2, these do not reflect the design and construction of an individual motor. By its nature, stray-load loss is indeed machine-specific and any arbitrary allocation for this loss is unjustifiable when measurements can be made [12].

With regard to the rotor conductor loss, and friction and windage losses, both standards share the same techniques and make no meaningful difference between the two.

\section{Testing Procedures and Human Factors}

There are some distinctions between the two standards in their definitions of conducting no-load and load tests.

IEEE 112 Method B specifies the following conditions.

1) When input power varies within $3 \%$ measured at two successive $30 \mathrm{~min}$ intervals with no load applied, thermal equilibrium is assumed. No-load test is carried out from $125 \%$ of rated voltage down to the voltage point, where voltage reduction would further increase the current, with no specified number of total testing points.

2) When measured machine temperature varies within $1{ }^{\circ} \mathrm{C}$ at 30 min intervals with rated load applied, thermal equilibrium is achieved. Rated and part-load tests are subsequently conducted with six decreasing torque readings from $150 \%$ down to $25 \%$ of the rated load torque.

3) It is advisable to take several readings at each voltage or load point in short periods of time and to average the results for a more accurate value.

4) Stator winding resistances are derived from the reference resistance and actual temperature rises under no-load and load conditions. Temperature sensors can be mounted onto two end-winding connections, in the stator slot, or buried in the core lamination although it is preferred to install at the hottest part of the machine. 
IEC 60034-2-1 specifies the following conditions.

1) When thermal equilibrium is assumed, no-load test is taken with at least four points equally spaced between $60 \%$ and $125 \%$ (including $100 \%$ ) and at least three points equally spaced between $20 \%$ and $50 \%$ of rated voltage.

2) When measured machine temperature varies within $2^{\circ} \mathrm{C} / \mathrm{h}$ with rated load applied, thermal equilibrium is achieved. Four load points are read approximately equally spaced between $25 \%$ and $100 \%$ (including 100\%) and two values equally spaced above $100 \%$ and not exceeding $150 \%$ of rated load. Rated and part-load tests are carried out from the highest load to the lowest in descending order. These tests should be performed as quickly as possible to minimize temperature changes in the motor.

3) Preferably, the winding temperature is determined by the direct measurement upon the rated load test using the shortest possible time by the extrapolation procedure. After the lowest load point is processed, another reading of the winding temperature is recorded. The two readings are used to predict winding resistances for all other loads. Alternatively, the winding temperature can also be measured with temperature sensors, similar to the IEEE procedures. However, there is no definition where the sensors should be attached to obtain an average winding temperature.

Human errors arise from interpreting the standard and test procedures, undertaking the practical measurements, and processing test results. For instance, the measurement error when the instrument is not used properly is attributed to human errors. However, defining a testing standard would be relatively straightforward if everyone who were using exactly the same measuring equipment had the same basic test rig and supply capability, relative to the test motors. Unfortunately, this is not the case in the real world and it becomes impossible to fully define a testing procedure within a standard although, of course, the procedural definitions are made as rigid as possible.

From the procedural definitions of the two standards, there are several issues that can be raised. First, for most induction motors with rating below $150 \mathrm{~kW}$, stator joule loss is likely to be the single greatest loss component. It is self-evident how important it is to determine the stator winding resistance with precision under any conditions. Nevertheless, the way the IEC standard predicts stator winding resistances is open to human interferences in the test process. On the one hand, taking a measurement too quickly at each part-load change would lead to errors if the transient has not had time to stabilize sufficiently. On the other hand, taking a measurement too slowly at each part-load would alter the operational condition that is set to be the rated load. In this respect, IEEE 112 provides a relatively accurate method to determine the stator winding resistance by using temperature sensors to obtain local winding temperatures.

Second, the location of the sensors inserted in the machine brings about deviations substantially, particularly when the machine is experiencing a high rate of temperature change. In general, the temperature difference between end-winding conductors, stator slots, and core laminations can be easily in excess of $5{ }^{\circ} \mathrm{C}$. Indeed, IEEE 112 is already better than the IEC counterpart since the former at least suggests obtaining the highest
TABLE II

LIST OF FEATURES OF IEEE 112 AND IEC 60034-2-1

\begin{tabular}{|l|c|c|}
\hline \multicolumn{1}{|c|}{ Features } & IEEE 112-B & IEC 34-2-1 \\
\hline Segregation of losses & $\sqrt{ }$ & $\sqrt{ }$ \\
\hline Temperature sensor positioned & $\sqrt{ }$ & $\times$ \\
\hline Ambient temperature reference & $25^{\circ} \mathrm{C}$ & $25^{\circ} \mathrm{C}$ \\
\hline Stator winding R corrected & $\sqrt{ }$ & $\sqrt{ }$ \\
\hline Slip corrected & $\sqrt{ }$ & $\sqrt{ }$ \\
\hline Core loss with voltage drop compensated & $\times$ & $\sqrt{ }$ \\
\hline Stray-loss linear regression analysis & $\sqrt{ }$ & $\sqrt{ }$ \\
\hline Stray-loss correlation coefficient & 0.9 & 0.95 \\
\hline Torque meter corrected & $\sqrt{ }$ & $\times$ \\
\hline Dynamometer corrected & $\times$ & $\sqrt{ }$ \\
\hline Output power corrected & $\sqrt{ }$ & $\sqrt{ }$ \\
\hline
\end{tabular}

temperature for the stator windings while there is no detail given in the latter. However, the IEEE method may only give a good approximation of the winding resistance but not a precise one. In essence, the thermal dynamics of the machine is complex so that the rate of temperature change is significantly different at different machine locations relative to the airflow paths. It may be accurate to install several sensors at various parts of the stator winding for a mean value, or ultimately, to use a direct online resistance measurement system [14], [15].

Third, the number of voltage or load points performed in the test by the IEEE standard is also open to human interpretations. Although the IEC standard specifies six approximately equally spaced points between $20 \%$ and $150 \%$, the test results are actually plotted against load torque squared for deriving the stray-load loss. It is obvious that higher load points would carry a greater weighting factor over lower ones when extrapolating a linear line to zero torque, owing to the magnifying effect by the square function. A similar case occurs for no-load tests in specifying the voltage points so as to determine friction and windage losses by the linear regression technique.

Major similarities and differences of IEEE 112 and IEC60034-2-1 are summarized in Table II.

\section{EXPERIMENTAL FACILITIES}

A schematic of the test rig for standard motor testing used in this study is shown in Fig. 2. This test rig consists of a dc load machine coupled to the test motor by a torque transducer mounted in a Carden shaft. There are no additional bearings between the torque transducer and the test motor. Armature current control using a Ward-Leonard system ensures smooth torque from the dc machine even at light load. The ac supply to the test motor is provided by an ac generator, which is driven by an inverter-fed, synchronous motor. Coupled to the same shaft as the generator and synchronous motor is a dc machine that forms part of the Ward-Leonard system and that reclaims energy from the test motor. This configuration is capable of providing precise and constant supply frequency. The automated voltage regulator of the generator gives voltage control from $0 \%$ right through to $130 \%$ of the nominal rated value. Supply imbalance and distortion are negligible with a balanced load.

In conjunction with the test rig, a calorimeter is also employed for validation of the power loss measurement, as also shown 


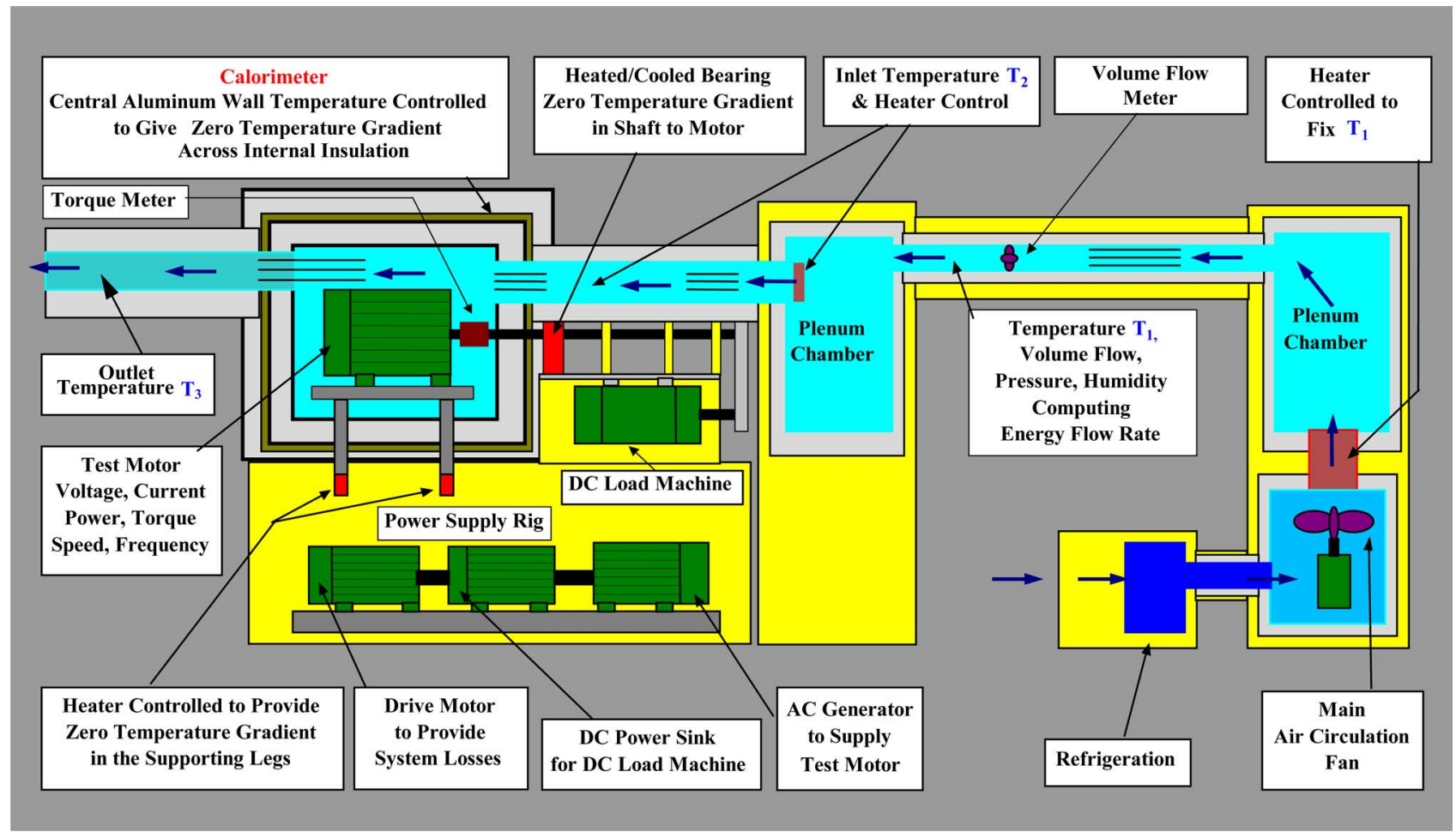

Fig. 2. Schematic of the test rig and the $30 \mathrm{~kW}$ calorimeter [16].

in Fig. 2. This calorimeter is basically an airtight thermally insulated enclosure with a sandwich structure. The induction motor is placed in the calorimeter for test while the airflow is arranged to pass through the calorimeter and to exhaust the heat generated by the motor. When thermal equilibrium is attained and all the heat leakage through the walls and connection paths are prevented or calibrated, the total power loss of the test motor is assumed to be the heat loss extracted by the air, which is computed from the air's thermal properties measured at the entry and exit ports. More details of this calorimeter can be found in [16].

The calorimeter can provide an alternative but high-precision means of power loss measurement. Unlike input-output methods, its accuracy is independent of motor power rating, excitation, and supply conditions [16]. However, the calorimetric tests are costly and all of long duration. Currently, this calorimeter can measure power losses to an overall accuracy better than $0.2 \%$, but is limited to induction motors of approximately $30 \mathrm{~kW}$.

\section{UnCERTAINTY IN THE STANDARD METHODS}

In a scientific measurement, the associated error commonly comprises three components

$$
\xi=\xi_{i}+\xi_{m}+\xi_{h}
$$

where $\xi$ is the overall measurement error, and $\xi_{i}, \xi_{m}$, and $\xi_{h}$ are the instrumental, methodological, and human errors, respectively.

In machine testing, the first two uncertainty sources arise from the instrumental accuracy, methodologies, and testing procedures defined by the standards. The human error is associated to the ways the personnel interpret the standards, conduct the test, and process test results.

Previously, the worst case estimation (WCE) [17], [18] has been employed for the evaluation of measurement uncertainty. For example, for estimating the efficiency, the following equation is used:

$$
\text { efficiency }=\frac{P_{\text {out }}}{P_{\text {in }}}=\frac{P_{\text {out }}\left(1 \pm e_{1} \pm e_{2} \pm \cdots \pm e_{m}\right)}{P_{\text {in }}\left(1 \pm e_{a} \pm e_{b} \pm \cdots \pm e_{n}\right)}
$$

where $e_{1}, e_{2}, \ldots, e_{m}$ are the percent errors in the measured variables associated with the computation of output power, and $e_{a}, e_{b}, \ldots, e_{n}$ are those associated with input power.

The maximum and minimum efficiency values can be easily determined and then used to estimate the spread of measured efficiency. In effect, this method is to summarize all the possible and maximum instrument-related uncertainties present in a measurement with reference to the instrumental accuracy. Obviously, this represents an overestimation of the error and is unlikely to occur in reality.

As an improvement, an RPBE is proposed for assessing uncertainty in the losses and efficiency. This technique considers the differing influence and significance of each measured variable, and summarizes all the major uncertainty contributors in quadrature addition, with reference to the instrumental accuracy of these variables specified in the standards.

When a number of instruments are involved in a measurement, a multivariable equation can be used to represent this complex system

$$
y=f\left(x_{i}, z_{j}\right)
$$


where $y$ is the output variable (e.g., efficiency), $x_{i}(i=1, \ldots, n)$ are the input variables, and $z_{j}(j=1, \ldots, m)$ represent additive noise that is not purely made up of bias levels.

A perturbation $\Delta x$ in the independent variable $x$ will lead to a deviation $\Delta y$ in $y$. The influence coefficient of the variable $x$ is defined as [19]

$$
I_{x}=\frac{\Delta y / y}{\Delta x / x_{i}}=\frac{\partial f}{\partial x_{i}} \frac{x_{i}}{y} .
$$

Provided all uncertainties are independent and random, the absolute error of the measurement at the output $y$ may be written as

$$
\Delta y=y \sum_{i=1}^{n} I_{x_{i}} \frac{\Delta x_{i}}{x_{i}}+\sum_{j=1}^{m} \frac{\partial f}{\partial z_{j}} z_{j} .
$$

Thus, the WCE for $y$ can be expressed as

$$
\frac{\Delta y}{y}=\sum_{i=1}^{n} I_{x_{i}} \frac{\Delta x_{i}}{x_{i}}+\frac{1}{y} \sum_{j=1}^{m} \frac{\partial f}{\partial z_{j}} z_{j} .
$$

The overall RPBE can be defined as

$$
\frac{\Delta y}{y}=\sqrt{\sum_{i=1}^{n}\left(I_{x_{i}} \frac{\Delta x_{i}}{x_{i}}\right)^{2}+\frac{1}{y^{2}} \sum_{j=1}^{m}\left(\frac{\partial f}{\partial z_{j}} z_{j}\right)^{2} .}
$$

In the case of calculating an induction motor's losses and efficiency (output variables), it is necessary to measure voltage, current, power, frequency, torque, speed, resistance, temperature, and other input variables. Using (5), each individual input's influence coefficient on an output can be computed. The significance of this input variable is given by multiplying its influence coefficient by its measurement accuracy defined by the standard method. By repeating this process, all the measured variables are evaluated and become comparable. More importantly, the "shortest bar in the bucket" can be identified by rating the input variables' significances. If all the error sources are summed up in quadrature addition using (8), an overall realistic error in the output variable can be calculated.

The advantages of identifying the significance of each individual error source are twofold. First, it can be used in combination to assess the standard methods in terms of measurement accuracy and result spread. Second, it can be used to guide measurement error mitigation measures. That is, targeting these prime error sources is a cost-effective method to improve the overall measurement accuracy.

\section{RESULTS AND DISCUSSIONS}

Six induction motors rated at $5.5,11,45,90,132$, and $150 \mathrm{~kW}$ are carefully tested following the standard input-output methods defined in IEEE 112-B and 60034-2-1. They are labeled A-F and the details are given in the Appendix. Of the six motors, a four-pole, $50 \mathrm{~Hz}, 5.5 \mathrm{~kW}$ motor (motor A) is also subjected to calorimetric tests within the $30 \mathrm{~kW}$ calorimeter.

The standard test procedures are based on no-load, full-load, and part-load tests. Part-load tests are required to be taken as quickly as possible in both standards, from the highest load to

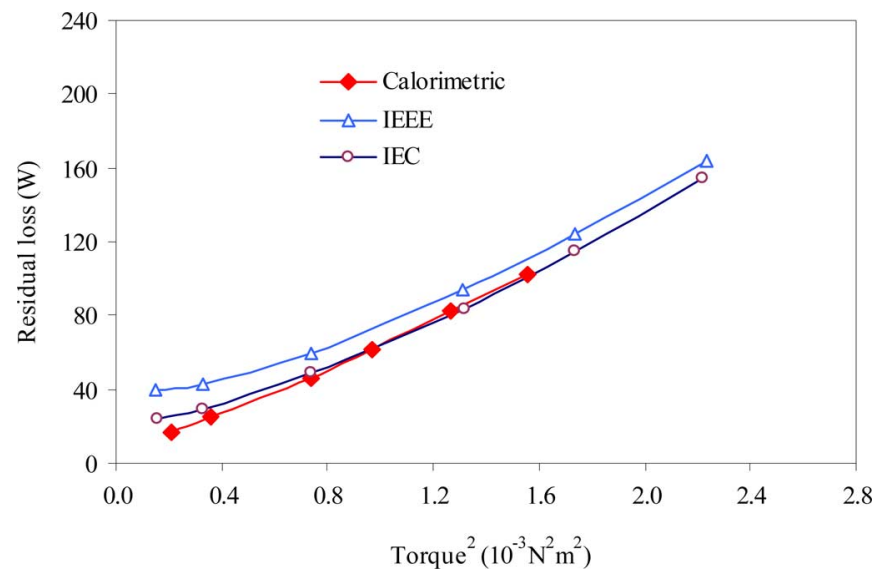

Fig. 3. Comparison of standard input-output and calorimetric methods.

the lowest, following a steady-state rated load test, i.e., partload tests are essentially conducted at the temperature of the machine related to the full-load condition. Yet, in the calorimetric tests, the part-load results correspond to the steady-state machine temperature associated with the part-load condition of operation. This might lead to some differences between the standard and calorimetric approaches, especially for those light loads.

\section{A. Calorimetric Tests}

As discussed previously, the calorimeter can provide accurate results for total power loss. But loss segregation still relies on other methods. In this case, IEEE 112-B is used. Since stray-load loss in the induction motor is a sensitive component derived from subtracting the identifiable losses from the total power loss, it is, thus, used in this study for comparison between calorimetric and input-output methods in terms of detecting a small loss change. Test results are plotted in Fig. 3 .

Fig. 3 presents the residual loss plotted against the square of load torque for motor A. Results for a range of load values including $25 \%, 50 \%, 75 \%, 85 \%, 100 \%$, and $110 \%$ are obtained by the calorimeter along with two sets of IEEE 112-B and IEC 60034-2-1 test results that extend load points further to $130 \%$.

Clearly, Fig. 3 gives a good impression of the shape of the residual loss curve that is forced to fit a straight line. The figure also shows a good agreement between the residual loss values obtained by the calorimetric technique and standard inputoutput methods. It can be seen that the calorimetric results present a linear curve shape going through the zero load points while the IEEE and IEC results give a slight curvature at light loads and a zero offset, primarily due to the difficulty of the standard methods to determine small power loss, and in particular, an inappropriate tracing of stator winding temperatures (or resistances) when the motor is undertaking a rapid temperature decrease from reducing loads.

\section{B. Power Loss Results}

Power loss results are given in Table III. All loss components, except friction and windage losses in the table, are corrected 
TABLE III

LOSSES AND EFFICIENCY BY IEEE 112-B AND IEC 60034-2-1 STANDARDS

\begin{tabular}{|c|c|r|r|r|r|r|r|}
\hline Motor & Std & Stator $^{2} \mathrm{R}$ & Rotor $\mathrm{I}^{2} \mathrm{R}$ & Core loss & F\&W & Stray loss & Efficiency \\
\hline \multirow{2}{*}{$A$} & IEEE & $411.2 \mathrm{~W}$ & $212.9 \mathrm{~W}$ & $131.5 \mathrm{~W}$ & $22.5 \mathrm{~W}$ & $72.8 \mathrm{~W}$ & $86.7 \%$ \\
\cline { 2 - 8 } & IEC & $409.4 \mathrm{~W}$ & $213.3 \mathrm{~W}$ & $120.4 \mathrm{~W}$ & $21.8 \mathrm{~W}$ & $80.2 \mathrm{~W}$ & $86.7 \%$ \\
\hline \multirow{2}{*}{$B$} & IEEE & $556.1 \mathrm{~W}$ & $238.5 \mathrm{~W}$ & $269.1 \mathrm{~W}$ & $35.3 \mathrm{~W}$ & $120.5 \mathrm{~W}$ & $90 \%$ \\
\cline { 2 - 8 } & IEC & $557.7 \mathrm{~W}$ & $238.6 \mathrm{~W}$ & $265.2 \mathrm{~W}$ & $35.9 \mathrm{~W}$ & $135.5 \mathrm{~W}$ & $89.9 \%$ \\
\hline \multirow{2}{*}{$C$} & IEEE & $801.8 \mathrm{~W}$ & $697 \mathrm{~W}$ & $730.9 \mathrm{~W}$ & $386.4 \mathrm{~W}$ & $363.1 \mathrm{~W}$ & $93.8 \%$ \\
\cline { 2 - 8 } & IEC & $801.3 \mathrm{~W}$ & $696.8 \mathrm{~W}$ & $722.1 \mathrm{~W}$ & $387.6 \mathrm{~W}$ & $378 \mathrm{~W}$ & $93.8 \%$ \\
\hline \multirow{2}{*}{$D$} & IEEE & $1362.8 \mathrm{~W}$ & $829.2 \mathrm{~W}$ & $1645 \mathrm{~W}$ & $719.5 \mathrm{~W}$ & $520.4 \mathrm{~W}$ & $94.6 \%$ \\
\cline { 2 - 8 } & IEC & $1361.4 \mathrm{~W}$ & $829.3 \mathrm{~W}$ & $1633 \mathrm{~W}$ & $718.1 \mathrm{~W}$ & $539.7 \mathrm{~W}$ & $94.6 \%$ \\
\hline \multirow{2}{*}{$E$} & IEEE & $2357.6 \mathrm{~W}$ & $1704.8 \mathrm{~W}$ & $1925.3 \mathrm{~W}$ & $3434 \mathrm{~W}$ & $475.1 \mathrm{~W}$ & $93 \%$ \\
\cline { 2 - 8 } & IEC & $2359.7 \mathrm{~W}$ & $1705.2 \mathrm{~W}$ & $1891.6 \mathrm{~W}$ & $3431 \mathrm{~W}$ & $511.4 \mathrm{~W}$ & $93 \%$ \\
\hline \multirow{2}{*}{$F$} & IEEE & $1981.1 \mathrm{~W}$ & $1017.6 \mathrm{~W}$ & $2118.2 \mathrm{~W}$ & $772.9 \mathrm{~W}$ & $1112 \mathrm{~W}$ & $95.6 \%$ \\
\cline { 2 - 7 } & IEC & $1983.9 \mathrm{~W}$ & $1017.3 \mathrm{~W}$ & $2075.1 \mathrm{~W}$ & $772.1 \mathrm{~W}$ & $1149 \mathrm{~W}$ & $95.5 \%$ \\
\hline
\end{tabular}

according to the IEEE and IEC standards. Stray-load losses are obtained from smoothing the residual losses and removing the zero offsets.

As shown in Table III, there are no meaningful distinctions in rotor conductor loss, and friction and windage losses between IEEE 112-B and IEC 60034-2-1 because both the methods use exactly the same techniques. Among the six motors, the distinctions in stator joule loss are insignificant. Although the determinations of stator winding resistance and/or temperature are quite different between the two standards, the actual stator conductor loss results are still close, almost within the measurement uncertainty the instruments can measure. It may be said that, as long as the standard methods are followed strictly, either standard can provide relatively accurate values for stator winding resistance, especially for the rated load condition. However, testers' personal experience will play a role in obtaining these data for other load conditions using the IEC standard where its procedures are defined loosely.

Conversely, in determining the core loss, the IEC standard specifies a rather detailed procedure. By taking account of the stator resistive voltage drop in core loss determination, this standard will give lower but more accurate core loss values than the IEEE standard. Clearly, this is the case for all six motors under test. As can be seen in Table III, the differences in core loss results between the two methods are in the range of 4-43 W, typically within a ratio of $1-2 \%$ of the core losses except for motor $\mathrm{A}$, which is a staggering $8 \%$.

Nonetheless, accurate determination of core loss by the IEC method does not naturally lead to an accurate efficiency figure. This is due to the nature of stray-load loss that represents the remainder of loss segregation. In fact, a reduction in core loss will appear as an increase in stray-load loss even after power loss corrections. As illustrated in Table III, stray-load loss for all motors increases by $7-37 \mathrm{~W}$ compared with the IEEE ones, reflecting the similar decreases in core losses.

\section{Efficiency Results}

It is also shown in Table III that, for these six motors under test, the efficiency results are exactly the same between the IEEE and IEC methods for motors A, C, D, and E. There is a $0.1 \%$ difference for motors B and F. In fact, the biggest difference can be found in the efficiency values other than rated, especially at the highest loads. Therefore, the rated efficiency alone is not sufficient to describe a motor's performance, since it is highly unlikely for an induction motor to operate under that rated condition in service.

From this limited number of induction motors, it may be concluded that a high degree of harmonization has already been achieved between IEC 60034-2-1 and IEEE 112 standards.

\section{Uncertainty Levels}

Using WCE and RPBE methods described previously, the measurement uncertainties in machine efficiency are studied in a MATLAB program, including those uncertainties resulting from measurements of voltage, current, power, torque, speed, frequency, resistance, and temperature. This is done by assessing the impact of each measurement uncertainty on the machine efficiency results and by adding their significances in a quadrature manner in terms of efficiency values.

These results are also given in Table I. It can be seen that, provided these standard methods are strictly followed, IEEE 112-B is capable of determining the machine efficiency to an accuracy of $0.17 \%$ with the worst case error of $0.31 \%$ while IEC $60034-2-1$ can also provide an accuracy of $0.18 \%$ with the worst case error of $0.33 \%$. A $0.1 \%$ difference for motors B and F falls well in this error range. It should be pointed out that these uncertainty analyses focus on instrumentation errors only. In practice, the overall measurement errors are generally greater and mainly due to human factors [20].

It is obvious that these test results have validated the new IEC standard in terms of detecting a very small loss in induction motors and providing accurate efficiency results.

\section{CONCLUSION}

A comparative study of IEEE 112 and IEC 34-2-1 standards for induction motor efficiency evaluation has been presented. Test results on six induction motors with ratings between 5.5 and $150 \mathrm{~kW}$ have verified the effectiveness of the new IEC standard 60034-2-1, which can offer similar efficiency values to the IEEE counterpart as long as the procedures are followed strictly. It can also be said that IEC 60034-2-1 has well aligned with IEEE 112. However, the two standards present some distinctions in determining stator conductor loss, core loss, and stray-load loss, but have no differences in determining rotor conductor loss, friction and windage losses. The differences in rated stator conductor losses are virtually within the measurement tolerance while those in core loss and stray-load loss are relatively significant. Compared to IEEE 112, the IEC standard can provide more accurate but lower core loss values, and thus, higher stray-load loss values. Clearly, the rated efficiency values for the two standards are approximately the same since the overall power losses by the standard methods are still similar.

In this study, power losses have been validated by calorimetric approach and efficiency results are examined by the proposed RPBE technique. Based on test results from these six motors, it may be concluded that instrumentation errors alone are not 
greater than $0.2 \%$ for IEEE 112-B and IEC 60034-2-1. The greater discrepancies in practical measurements should be attributed to methodological and human errors. As a result, the procedural definitions in a standard should be made as stringent as possible to minimize these errors.

\section{APPENDIX}

LIST OF TEST MACHINES

\begin{tabular}{|l|r|r|r|r|r|r|}
\hline Motor & \multicolumn{1}{c|}{$\mathbf{A}$} & \multicolumn{1}{c|}{ B } & \multicolumn{1}{c|}{ C } & \multicolumn{1}{c|}{ D } & \multicolumn{1}{c|}{ E } & \multicolumn{1}{c|}{ F } \\
\hline$k W$ & 5.5 & 11 & 45 & 90 & 132 & 150 \\
\hline Pole No. & 4 & 4 & 2 & 4 & 2 & 4 \\
\hline$H z$ & 50 & 50 & 50 & 50 & 50 & 50 \\
\hline$V$ & 400 & 400 & 400 & 400 & 400 & 400 \\
\hline$A$ & 11 & 24 & 75 & 163 & 226 & 255 \\
\hline$R P M$ & 1450 & 1455 & 2955 & 1485 & 2965 & 1487 \\
\hline
\end{tabular}

\section{ACKNOWLEDGMENT}

The author would like to acknowledge the helpful discussions with Prof. K. J. Bradley of Nottingham University on the preparation of this paper.

\section{REFERENCES}

[1] P. Kelly-Detwiler and G. Soares, "Harmonization of induction motor efficiency standards in Latin America," in Proc. Conf. Rec. IEEE Int. Electr. Mach. Drives Conf., May18-21, 1997, pp. WC1/4.1-WC1/4.3.

[2] W. Cao, "Accurate measurement and evaluation of losses and efficiency of new and rewound induction motors," Ph.D. dissertation, Univ. Nottingham, Sep. 2004.

[3] B. Renier, K. Hameyer, and R. Belmans, "Comparison of standards for determining efficiency of three phase induction motors," IEEE Trans. Energy Convers., vol. 14, no. 3, pp. 512-517, Sep. 1999.

[4] A. T. de Almeida, F. T. E. Ferreira, J. F. Busch, and P. Angers, "Comparative analysis of IEEE 112-B and IEC 34-2 efficiency testing standards using stray load losses in low voltage three-phase, cage induction motors," IEEE Trans. Ind. Appl., vol. 38, no. 2, pp. 608-614, Mar./Apr. 2002.

[5] B. C. Johnson, D. G. Dunn, and R. Hulett, "Seeking global harmony in standards," IEEE Ind. Appl. Mag., vol. 10, no. 1, pp. 14-20, Jan./Feb. 2004.

[6] IEEE Standard Test Procedure for Polyphase Induction Motors and Generators (ANSI), IEEE Std 112-2004 (IEEE 112-1991, 1996).

[7] Energy Efficiency Test Methods for Three-Phase Induction Motors, CSA Std C390-93, Jul. 1993.

[8] Amendments 1: 1995 and Amendments 2: 1996, General Requirements for Rotating Electrical Machines-Part 102: Methods for Determining Losses and Efficiency From Tests (Excluding Machines for Traction Vehicles), IEC 34-2: 1972 (IEC 34-2A 1974) (BS EN 60034-2).
[9] E. Levi, Polyphase Motors: A Direct Approach to Their Design. New York: Wiley, 1984.

[10] C. N. Glew, "Stray load losses in induction motors: A challenge to academia," Power Eng. J. [see also Power Eng.], vol. 12, no. 1, pp. 27-32, Feb. 1998.

[11] H. Auinger, "Determination and designation of the efficiency of electrical machines," Power Eng. J. [see also Power Eng.], vol. 13, no. 1, pp. 15-23, Feb. 1999.

[12] W. Cao, K. J. Bradley, and J. Allen, "Evaluation of additional loss in induction motors consequent upon repair and rewinding," Proc. Inst. Electr. Eng. Electr. Power Appl., vol. 153, no. 1, pp. 1-6, Jan. 2006.

[13] Rotating Electrical Machines-Part 2-1: Standard Methods for Determining Losses and Efficiency From Tests (Excluding Machines for Traction Vehicles), IEC 60034-2-1: 2007 (BS EN 60034-2-1).

[14] V. S. Gribakin and Y. N. Maslov, "A bridge method for automated measurement of the winding resistance of electric machines under load," Meas. Techn. USSR, vol. 25, no. 4, pp. 344-347, 1982.

[15] S. B. Lee and T. G. Habetler, "An online stator winding resistance estimation technique for temperature monitoring of line-connected induction machines," IEEE Trans. Ind. Appl, vol. 39, no. 3, pp. 685-694, May/Jun. 2003.

[16] W. Cao, K. J. Bradley, and A. Ferrah, "Development of a high-precision calorimeter for measuring power loss in electrical machines," IEEE Trans. Instrum. Meas., vol. 58, no. 3, pp. 570-577, Mar. 2009.

[17] R. S. Colby and D. L. Flora, "Measured efficiency of high efficiency and standard induction motors," in Conf. Rec. IEEE Ind. Appl. Soc. Annu. Meet., Oct. 7-12, 1990, vol. 1, pp. 18-23.

[18] D. R. Turner, K. J. Binns, B. N. Shamsadeen, and D. F. Warne, "Accurate measurement of induction motor losses using balance calorimeter," Proc. Inst. Electr. Eng. Electr. Power Appl., vol. 138, no. 5, pp. 233-242, Sep. 1991.

[19] S. G. Rabinovich, Measurement Errors and Uncertainties: Theory and Practice, 3rd ed. New York: Springer-Verlag, 2005.

[20] K. J. Bradley, W. Cao, and J. Arellano-Padilla, "Evaluation of stray load loss in induction motors with a comparison of input-output and calorimetric methods," IEEE Trans. Energy Convers., vol. 21, no. 3, pp. 682-689, Sep. 2006.

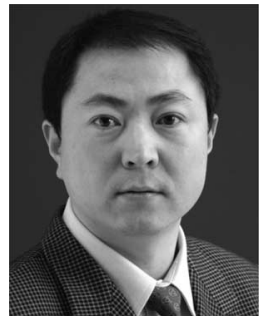

Wenping Cao (M'05) received the Ph.D. degree in electrical machines and drives from the University of Nottingham, Nottingham, U.K., in 2004.

Between January 2004 and January 2005, he was an Electrical Engineering Technologist with the University of Sheffield, Sheffield, U.K., and a Research Fellow with the University of Nottingham between January 2005 and February 2006. Currently, he is a Senior Lecturer with the University of Teesside, Tees Valley, U.K. His current research interests include energy efficiency improvements in the design, operation, and repair of electric machines and drives.

Dr. Cao is a member of the Institution of Engineering and Technology. 